\title{
Heteronuclear Cross-Relaxation under Dynamic Nuclear Polarization in Nicotine and Caffeine
}

\author{
V. Aladin ${ }^{1,2,3,4}$, P. A. Trenkler ${ }^{3}$ and B. Corzilius ${ }^{1,2,3,4}$ (D) \\ ${ }^{1}$ Institute of Chemistry, University of Rostock, Albert-Einstein-Straße 3a, 18059 Rostock, Germany, ${ }^{2}$ Department Life, Light \& \\ Matter, University of Rostock, Albert-Einstein-Straße 25, 18059 Rostock, Germany, ${ }^{3}$ Institute of Physical and Theoretical \\ Chemistry, Goethe University Frankfurt, Max-von-Laue-Str. 7, 60438 Frankfurt, Germany, and ${ }^{4}$ Institute of Biophysical \\ Chemistry, Goethe University Frankfurt, Max-von-Laue-Str. 9, 60438 Frankfurt, Germany \\ ${ }^{*}$ Corresponding author. Email: bjoern.corzilius@uni-rostock.de
}

(Received 01 February 2020; Revised 17 March 2020; Accepted 18 March 2020)

\begin{abstract}
Dynamic nuclear polarization (DNP) is a technique in magic-angle spinning (MAS) nuclear magnetic resonance (NMR) which leads to sensitivity enhancement and helps to overcome the issue of low polarization in detected nuclei. Recent research showed, that methyl groups, which show active reorientation dynamics and cause heteronuclear cross relaxation at typical DNP temperatures around $100 \mathrm{~K}$, may be used as a pinpoint source of polarization for selective and site-specific probing. In this study, we investigated the cross-relaxation behavior of methyl groups in nicotine and caffeine under DNP. These effects could be useful for investigating receptor/ligand binding.
\end{abstract}

Keywords: MAS-NMR; SCREAM-DNP; methyl dynamics; cross relaxation; biomolecules

\section{Related Article:}

Complex formation of the tetracycline-binding aptamer investigated by specific cross-relaxation under DNP.

V. Aladin, M. Vogel, R. Binder, I. Burghardt, B. Suess, and B. Corzilius: https://doi.org/10.1002/ anie.201811941

\section{Introduction}

The study of ligand binding with magic-angle spinning (MAS) NMR is challenging, as biomolecules made of same building blocks suffer from spectral overlap. Moreover, NMR has the issue of very low sensitivity as a result of low thermal spin polarization. DNP is a technique that allows overcoming the sensitivity problem (Lilly Thankamony, et al., 2017). Recently the effect of spontaneous ${ }^{1} \mathrm{H}_{-}{ }^{13} \mathrm{C}$ polarization transfer via heteronuclear cross-relaxation due to fast reorientation dynamics in a ${ }^{13} \mathrm{C}$ or ${ }^{15} \mathrm{~N}$ MAS direct polarization experiment under DNP was discovered (Daube et al., 2016; Hoffmann et al., 2017a, 2017b; Park et al., 2020). Further investigation showed that cross-relaxation-promoting methyl groups and the resulting Specific Cross Relaxation Enhancement by Active Motions under DNP (SCREAM-DNP) can be used as a tool for selective probing in biomolecules such as RNA (Aladin et al., 2019) and proteins (Mao et al., 2019).

\footnotetext{
(C) The Author(s) 2020. This is an Open Access article, distributed under the terms of the Creative Commons Attribution licence (http:// creativecommons.org/licenses/by/4.0/), which permits unrestricted re-use, distribution, and reproduction in any medium, provided the original work is properly cited.
} 
<smiles></smiles>

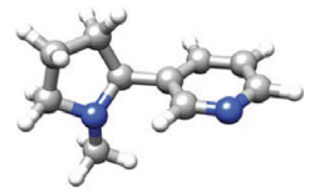<smiles>Cn1c(=O)c2c(ncn2C)n(C)c1=O</smiles>

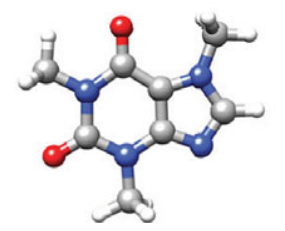

Figure 1. Structural formulas and ball-and-stick models of nicotine and caffeine.
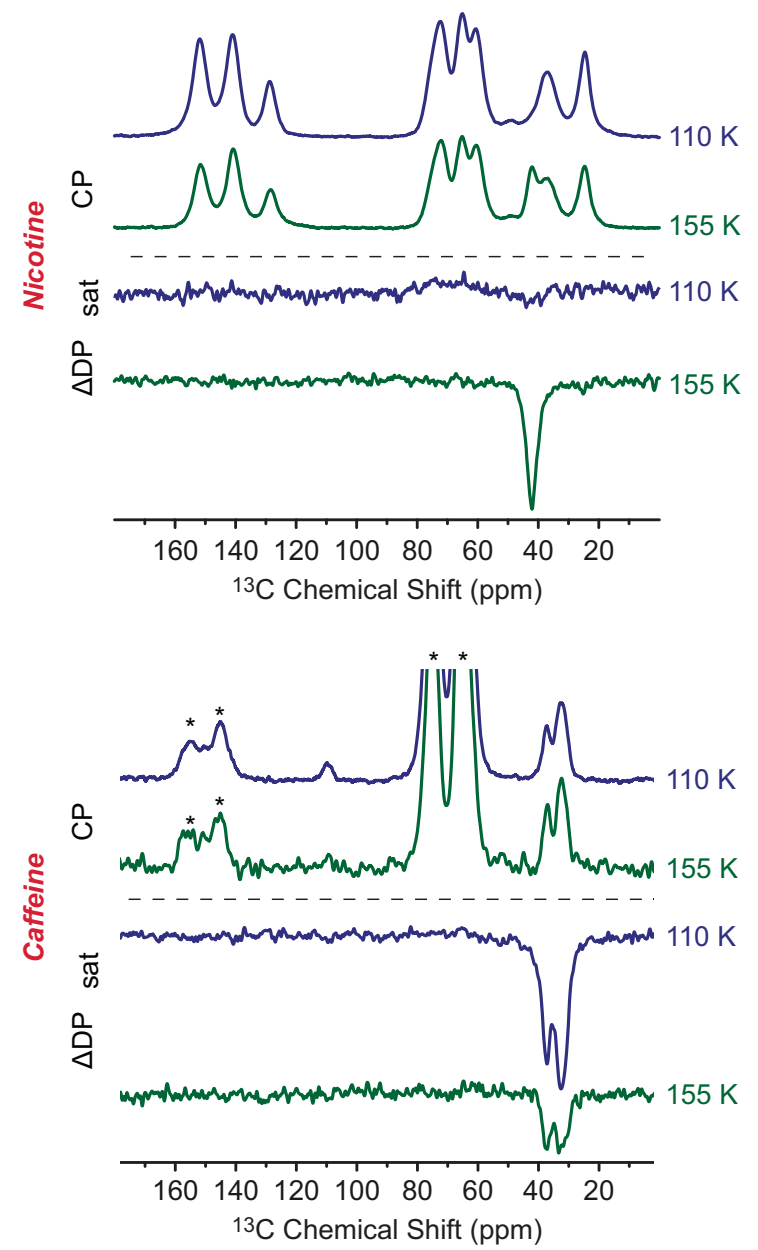

Figure 2. DNP-enhanced $\mathrm{CP}$ ( $3 \mathrm{~s}$ polarization time) and $\triangle \mathrm{DP}_{\text {sat }}$ ( $6 \mathrm{~s}$ polarization time) spectra at 110 and $155 \mathrm{~K}$ of nicotine and caffeine. Resonances stemming from glycerol are marked with asterisks.

This allows to overcome the drawback of typical unspecific DNP experiments such as cross polarization (CP) and direct polarization (DP), using dynamically active methyl groups as pinpoint sources of polarization. 


\section{Objective}

To further utilize SCREAM-DNP in biological systems and investigate receptor/ligand binding, suitable methyl groups have to be examined. Nicotine, mostly known as an agonist in acetylcholine receptors, and caffeine, which acts as adenosine receptor antagonist, are methyl-carrying ligands that could pose interesting targets for such binding studies (see Figure 1). Here, we explored the behavior of methyl group dynamics in nicotine and caffeine by SCREAM-DNP. As methyl reorientation is a temperatureactivated process under typical DNP conditions, differences in rotational hindrance play an important factor in cross-relaxation efficiency (Aladin \& Corzilius, 2019). Therefore, we investigated SCREAMDNP in these two systems at $110 \mathrm{~K}$ and $155 \mathrm{~K}$.

\section{Methods}

Nicotine and caffeine (Sigma-Aldrich) in natural isotope abundance were dissolved in $\mathrm{D}_{8^{-}}{ }^{12} \mathrm{C}_{3}$-glycerol (98\% D, 99.95\% ${ }^{12} \mathrm{C}$, Euriso-Top) $/ \mathrm{D}_{2} \mathrm{O} / \mathrm{H}_{2} \mathrm{O}$ mixture (60/30/10 vol.-\%) containing $10 \mathrm{mM}$ AMUPol (SATT Sud-Est, Marseille (Sauvée et al., 2013)) with final concentrations of $0.1 \mathrm{M}$ and $1 \mathrm{M}$ for caffeine and nicotine, respectively.
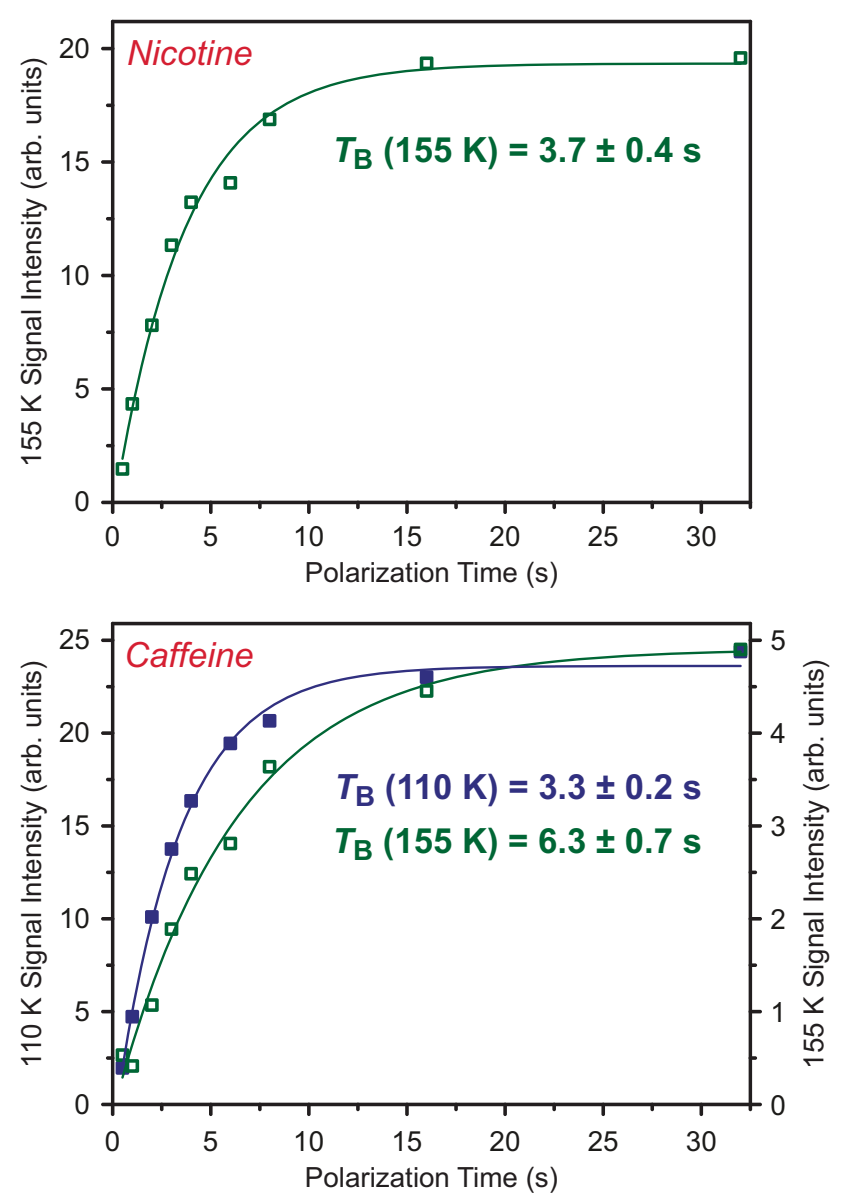

Figure 3. $\Delta D P_{\text {sat }}$ build-up curves of methyl resonances at $110 \mathrm{~K}$ in nicotine and at 110 and $155 \mathrm{~K}$ in caffeine. The signal intensity was determined by integration over the single methyl resonance in nicotine and over all three methyl resonances in caffeine (see Figure S1). 
All experiments were performed on a Bruker AVANCE II DNP spectrometer $\left(400.2 \mathrm{MHz}{ }^{1} \mathrm{H}\right)$ and $263.4 \mathrm{GHz}$ gyrotron microwave frequency under $8 \mathrm{kHz}$ MAS. CP experiments were performed with $3 \mathrm{~s}$ polarization time. For each sample and temperature (110 and $155 \mathrm{~K}) \mathrm{DP}$ as well as DP with proton saturation $\left(\mathrm{DP}_{\text {sat }}\right)$ experiments were recorded for different polarization times. The mathematical subtraction of $\mathrm{DP}$ and $\mathrm{DP}_{\text {sat }}$ spectra results in spectral contributions of magnetization stemming exclusively from cross relaxation $\left(\Delta \mathrm{DP}_{\text {sat }}\right)$. The used pulse sequences and further experimental parameters are analogous as described elsewhere (Aladin et al., 2019; Aladin \& Corzilius, 2019).

\section{Results}

As seen in Figure 2 the sole $\mathrm{CH}_{3}$ resonance in nicotine is broadened at $110 \mathrm{~K}$ due to interference by dynamics (Ni et al., 2017) and also does not show any significant SCREAM-DNP signal. By increasing the temperature to $155 \mathrm{~K}$ it now reveals both a distinct resonance in the $\mathrm{CP}$ as well as a strong SCREAM-DNP signal $\left(\Delta \mathrm{DP}_{\text {sat }}\right)$ with a build-up time constant of $3.7 \mathrm{~s}$ (Figure 3 ). Here it is unclear, if the missing $\Delta \mathrm{DP}_{\text {sat }}$ signal at $155 \mathrm{~K}$ is due to broadening beyond detectability or inefficient SCREAM-DNP transfer.

Contrary to this, all three methyl groups of caffeine show no significant broadening in $\mathrm{CP}$ and provide a strong SCREAM-DNP signal $\left(\triangle \mathrm{DP}_{\mathrm{sat}}\right)$ with a build-up constant of $3.3 \mathrm{~s}$ at $110 \mathrm{~K}$. In this case, the signal intensity due to cross relaxation in $\triangle \mathrm{DP}_{\text {sat }}$ drops with higher temperature and the build-up time increases to $6.3 \mathrm{~s}$ at $155 \mathrm{~K}$.

\section{Discussion}

In the case of nicotine the methyl reorientation is causing interference at $110 \mathrm{~K}$, resulting in homogeneous broadening; furthermore, significant polarization transfer by cross relaxation seems to be prevented. By increasing the temperature to $155 \mathrm{~K}$, this dynamic is accelerated and efficient cross relaxation occurs. The methyl dynamics in caffeine seem to be in the sufficiently fast limit regime already at $110 \mathrm{~K}$ in order to avoid interference and support efficient SCREAM-DNP. By increasing the temperature, the correlation time is shortened past the optimum $(\omega \tau \mathrm{c}=1)$. This is supported experimentally by the extended build-up time and reduced signal intensity.

\section{Conclusions}

The contrast between nicotine and caffeine may be explained by structural differences. In nicotine, the sterically demanding pyridine group can affect the methyl dynamics. Moreover, the hybridization of the methyl-carrying $\mathrm{N}$ in nicotine is $\mathrm{sp}^{3}$, whereas the relevant nitrogens in caffeine are $\mathrm{sp}^{2}$ hybridized with a larger CNC bond angle. Therefore, the methyl groups in caffeine are less sterically hindered. As a result, caffeine has an efficient SCREAM-DNP effect at $110 \mathrm{~K}$, while for nicotine a similar situation is only found at an increased temperature of $155 \mathrm{~K}$. Both ligands further could be useful for biomolecular complexspecific studies by SCREAM-DNP.

\section{Ethical Statement. N/A}

Funding Information. This work has been funded by the Deutsche Forschungsgemeinschaft through grants CO 802/2 and CO 802/4. We acknowledge support by the Center for Biomolecular Magnetic Resonance. (BMRZ, Frankfurt am Main).

Author Contributions. VA has designed all experiments, helped performing the experiments and has written the manuscript. PAT has performed all experiments. BC has supported the design of the experiments and has edited the manuscript.

Conflict of Interest. BC is a reviewing editor for Experimental Results. VA and PAT declare none.

Data availability statement. The NMR raw data as well as peak integrals used for build-up curves have been deposited at https://doi.org/10.5281/zenodo.3688628 under Creative Commons Attribution 4.0 International Public License.

Supplementary Materials. To view supplementary material for this article, please visit http://dx.doi.org/10.1017/exp.2020.17. 


\section{References}

Aladin, V., \& Corzilius, B. (2019). Methyl dynamics in amino acids modulate heteronuclear cross relaxation in the solid state under MAS DNP. Solid State Nuclear Magnetic Resonance, 99, 27-35. https://doi.org/10.1016/j.ssnmr.2019.02.004.

Aladin, V., Vogel, M., Binder, R., Burghardt, I., Suess, B., \& Corzilius, B. (2019). Complex formation of the tetracyclinebinding aptamer investigated by specific cross-relaxation under DNP. Angewandte Chemie International Edition in English, 58, 4863-4868. https://doi.org/10.1002/anie.201811941.

Daube, D., Aladin, V., Heiliger, J., Wittmann, J. J., Barthelmes, D., Bengs, C., Schwalbe, H., \& Corzilius, B. (2016). Heteronuclear cross-relaxation under solid-state dynamic nuclear polarization. Journal of the American Chemical Society, 138, 16572-16575. https://doi.org/10.1021/jacs.6b08683.

Hoffmann, M. M., Bothe, S., Gutmann, T., \& Buntkowsky, G. (2017). Unusual local molecular motions in the solid state detected by dynamic nuclear polarization enhanced NMR spectroscopy. The Journal of Physical Chemistry C, 121, 22948-22957. https://doi.org/10.1021/acs.jpcc.7b07965.

Hoffmann, M. M., Bothe, S., Gutmann, T., Hartmann, F. -F., Reggelin, M., \& Buntkowsky, G. (2017). Directly vs indirectly enhanced ${ }^{13} \mathrm{C}$ in dynamic nuclear polarization magic angle spinning NMR experiments of nonionic surfactant systems. The Journal of Physical Chemistry C, 121, 2418-2427. https://doi.org/10.1021/acs.jpcc.6b13087.

Lilly Thankamony, A. S., Wittmann, J. J., Kaushik, M., \& Corzilius, B. (2017). Dynamic nuclear polarization for sensitivity enhancement in modern solid-state NMR. Progress in Nuclear Magnetic Resonance Spectroscopy, 102-103, 120-195. https:// doi.org/10.1016/j.pnmrs.2017.06.002.

Mao, J., Aladin, V., Jin, X., Leeder, A. J., Brown, L. J., Brown, R. C. D., He, X., Corzilius, B., \& Glaubitz, C. (2019). Exploring protein structures by DNP-enhanced methyl solid-state NMR spectroscopy. Journal of the American Chemical Society, 141, 19888-19901. https://doi.org/10.1021/jacs.9b11195.

Ni, Q. Z., Markhasin, E., Can, T. V., Corzilius, B., Tan, K. O., Barnes, A. B., Daviso, E., Su, Y., Herzfeld, J., \& Griffin, R. G. (2017). Peptide and protein dynamics and low-temperature/DNP magic angle spinning NMR. Journal of Physical Chemistry B, 121, 4997-5006. https://doi.org/10.1021/acs.jpcb.7b02066.

Park, H., Uluca-Yazgi, B., Heumann, S., Schlogl, R., Granwehr, J., Heise, H., \& Schleker, P. P. M. (2020). Heteronuclear crossrelaxation effect modulated by the dynamics of $\mathrm{N}$-functional groups in the solid state under ${ }^{15} \mathrm{~N}$ DP-MAS DNP. Journal of Magnetic Resonance, 312, 106688. https://doi.org/10.1016/j.jmr.2020.106688.

Sauvée, C., Rosay, M., Casano, G., Aussenac, F., Weber, R. T., Ouari, O., \& Tordo, P. (2013). Highly efficient, water-soluble polarizing agents for dynamic nuclear polarization at high frequency. Angewandte Chemie International Edition, 52, 10858-10861. https://doi.org/10.1002/anie.201304657.

Cite this article: Aladin V, Trenkler PA, Corzilius B (2020). Heteronuclear Cross-Relaxation under Dynamic Nuclear Polarization in Nicotine and Caffeine Experimental Results, 1, e10, 1-8. https://doi.org/10.1017/exp.2020.17 


\section{Peer Reviews}

\section{Reviewing editor: Dr. Ausrine Bartasyte}

Burgundy Franche-Comté University, FEMTO-ST Institute, 26 rue de l'Epitaphe, Besançon, France, 25030

This article has been accepted because it is deemed to be scientifically sound, has the correct controls, has appropriate methodology and is statistically valid, and met required revisions.

doi:10.1017/exp.2020.17.pr1

\section{Review 1: Heteronuclear Cross-Relaxation under Dynamic Nuclear Polarization in Nicotine and Caffeine}

Reviewer: Markus Hoffmann (D)

SUNY Brockport

Date of review: 02 February 2020

Published online:

(C) The Author(s) 2020 This is an Open Access article, distributed under the terms of the Creative Commons Attribution licence http://creativecommons.org/licenses/by/4.0/), which permits unrestricted re-use, distribution, and reproduction in any medium, provided the original work is properly cited.

Conflict of interest statement. Reviewer declares none.

\section{Comment}

Comments to the Author: This is the first time for me reviewing for "Experimental Results" and I understand that there are word limits for each section. Within these limits the authors present adequately some spectral results concerning dynamic nuclear polarization, a timely subject area that receives increasing attention in current research. It appears that the amount of data is indeed too small to get published in a regular "normal sized" journal article, but too important not to get published at all. All sections are clear and well written.My specific recommendation is a relatively minor one. I believe it is important to point out that there has been evidence also for motions other than methyl rotation that can be active under the low temperatures of DNP experiments. Besides PEG mentioned in the article included in the references, cyclohexane also show heteronuclear cross relaxation even though neither of these molecules possess a methyl group. (Hoffmann, M. M.; Bothe, S.; Gutmann, T.; Buntkowsky, G., Unusual local molecular motions in the solid state detected by dynamic nuclear polarization enhanced NMR spectroscopy. J. Phys. Chem. C 2017, 121, 22948-22957.)The authors might find also important to note that heteronuclear cross-relaxation has very recently been observed between $1 \mathrm{H}$ and $15 \mathrm{~N}$. (Park, H.; Uluca-Yazgi, B.; Heumann, S.; Schlogl, R.; Granwehr, J.; Heise, H.; Schleker, P. P. M., Heteronuclear cross-relaxation effect modulated by the dynamics of $\mathrm{n}$-functional groups in the solid state under $(15) \mathrm{N}$ dp-mas DNP. J. Magn. Reson. 2020, 312, 106688.)

\section{Score Card}

Presentation 
Does the abstract correctly embody the content of the article? (25\%)

Does the introduction give appropriate context? (25\%)

Is the objective of the experiment clearly defined? (25\%)

Analysis

Does the discussion adequately interpret the results presented? (40\%)

Is the conclusion consistent with the results and discussion? (40\%)

Are the limitations of the experiment as well as the contributions of the experiment clearly outlined? $(20 \%)$ 


\section{Review 2: Heteronuclear Cross-Relaxation under Dynamic Nuclear Polarization in Nicotine and Caffeine}

Reviewer: Prof. Graziella Malandrino

SUNY Brockport

Date of review: 07 March 2020

Published online:

Conflict of interest statement. Reviewer declares none.

\section{Comment}

Comments to the Author: The manuscript reports on investigating the cross-relaxation behavior of methyl groups in nicotine and caffeine under the dynamic nuclear polarization in magic-angle spinning NMR.The objective is clearly defined in perspective of applications to biological systems and, specifically to the investigation of receptor/ligand binding. The results easily describe the carried out experiments and discussion section reports a clear interpretation of obtained results. Overall, the manuscript addresses a topic of interest with a scientifically sounding approach.

\section{Score Card}

Presentation

Is the article written in clear and proper English? (30\%)

Is the data presented in the most useful manner? $(40 \%)$

Does the paper cite relevant and related articles appropriately? (30\%)

Context

Does the abstract correctly embody the content of the article? (25\%)

Does the introduction give appropriate context? (25\%)

Is the objective of the experiment clearly defined? (25\%)

Analysis

Does the discussion adequately interpret the results presented? (40\%)

Is the conclusion consistent with the results and discussion? (40\%)

Are the limitations of the experiment as well as the contributions of the experiment clearly outlined? (20\%) 